\title{
EL BUTAQUE. DE ASIENTO POPULAR A ARQUETIPO DEL MUEBLE MEXICANO DEL SIGLO XX.
}

\begin{abstract}
THE BOUTAQUE: FROM POPULAR SEAT TO ARCHETYPE OF TWENTIETHCENTURY MEXICAN FURNITURE
\end{abstract}

Dra. Mercedes Josefina Hernández Padilla* Centro universitario de Arte, Arquitectura y Diseño

Universidad de Guadalajara

\section{Resumen}

Después de la Revolución Mexicana, se inició un programa de difusión de ciertos símbolos de identidad nacional para redefinir la mexicanidad. La búsqueda se expresó en bellas artes y artes decorativas, incluido el mobiliario. En este contexto, reapareció el "Butaque".

Arquitectos como Luis Barragán, William Spratling, Clara Porset y Manuel Parra, entre otros, propusieron sus propias interpretaciones de este tradicional asiento rural, insertándolo en un nuevo contexto sociocultural, convirtiéndola en una pieza representativa del mobiliario mexicano del siglo XX. A pesar de su importancia, no se han realizado muchos estudios o publicaciones sobre la pieza, y el misterio rodea su origen.

El objetivo de este trabajo es presentar una hipótesis sobre el origen del "butaque" en los códices coloniales, y revalorizarlo como un asiento mestizo, una combinación de técnicas y tecnologías de fabricación europeas con materiales, mano de obra y habilidad de los indígenas mexicanos, convirtiéndolo en una digna representación de la identidad cultural mexicana.

Palabras clave: Butaque, códice, identidad, mexicanidad

\section{Abstract}

Following the Mexican Revolution, a program began for the dissemination of certain symbols of national identity-to redefine the Mexicanity. The search was expressed in fine and decorative arts, including furniture. In this context, the "Butaque" chair reappeared.

Architects like Luis Barragán, William Spratling, Clara Porset, and Manuel Parra, among others, proposed their own interpretations of this traditional rural seat, inserting it into a new socio-cultural context, making it a representative piece of 20 th century Mexican furniture. Despite its significance, there have not been many studies or publications on the piece, and mystery surrounds it's origin.

The objective of this work is to present a hypothesis about the origin of the "butaque" in the colonial codices, and to revalue it as a mestizo seat, a combination of European manufacturing techniques and technologies with 
materials, labor and ability of the Mexican indigenous, making it a worthy representation of Mexican cultural identity.

Keywords: Mexican armchair, Codex, Identity, Mexicanity

\section{Introducción}

Al finalizar la Guerra de la Revolución Mexicana, con la creación de la Secretaría de Educación Pública en el año de 1921, a cargo de José Vasconcelos, se dio inicio a un programa cuyo principal objetivo fue la difusión de distintos símbolos de identidad nacional, buscando inicialmente en el mestizaje y poco después, en las culturas indígenas los elementos unificadores de las diversas clases sociales con el propósito de definir la llamada Mexicanidad ${ }^{1}$; esta búsqueda no se limitó a las bellas artes, de las cuales pueden nombrarse el Movimiento Muralista Mexicano, la arquitectura nacionalista, la música y el cine, sino que también las artes decorativas en general, y en lo particular el mobiliario, que a partir de la exposición y publicación denominada "Las artes populares de México"2, que dignificó a nivel de museo los objetos de uso cotidiano de manufactura artesanal ${ }^{3}$, hecho que contribuyó a la promoción y consolidación una identidad cultural, fundamentada en la filosofía estética de Vasconcelos.

Desde entonces y durante el resto del Siglo XX, se caracterizó al diseño y al mueble mexicano, así como a la identidad cultural mexicana, por sus raíces con el pasado mesoamericano y colonial, atado a las artes aplicadas y al llamado arte popular, revalorizando viejas formas, usos y funciones de diversas piezas de mobiliario, hasta entonces de uso extendido entre los grupos sociales más modestos.

Es en este contexto que reaparece el butaque, también conocido como silla Campeche; una silla de descanso de manufactura artesanal, utilizada en las regiones tropicales del golfo de México, y con algunas variantes de carácter regional, en diversas zonas rurales de México; estos asientos eran elaborados por los campesinos y peones en las haciendas para su propio uso, y para los señores, los manufacturaban en maderas y acabados de mejor calidad.

Desde finales de la década de 1920 y hasta 1970, arquitectos y diseñadores como Luis Barragán, William Spratling, Clara Porset, Michael van Beuren, Manuel Parra y Alejandro Rangel Hidalgo, propusieron sus propias interpretaciones de butaques que insertaron en un nuevo contexto sociocultural, conjuntando tradición, modernidad e identidad cultural en el mobiliario mexicano del siglo XX, traspasando las fronteras a través del menaje de las embajadas de México en el mundo, y hasta hace muy poco, de la residencia oficial de Los Pinos.

A pesar de su trascendencia, han sido escasos los estudios y publicaciones sobre el butaque, es poco lo que se conoce acerca de su origen, a diferencia de otros asientos de procedencia europea o americana; más su fabricación, uso, tipología, comercialización e incluso exportación ha sido posible rastrearlo desde finales del siglo XVII, en diversas regiones de México, el sur de los Estados Unidos y en las Islas del Caribe.

El objetivo del presente trabajo es presentar una hipótesis sobre el origen del butaque en los códices coloniales, y revalorarlo como un asiento mestizo, 
producto de la combinación de técnicas y tecnologías de manufactura europeas y materiales, mano de obra e ingenio del indígena mexicano, y por lo tanto, digno representante de la identidad cultural mexicana.

\section{Materiales y métodos}

Para este trabajo de investigación se utilizaron documentos escritos, diversas publicaciones referentes a la historia del arte mexicano, historia del mueble en México, así como artículos de revistas y otras publicaciones de carácter científico e histórico cuyo tema central fuera el mueble y/o las artes menores en México. La colección facsimilar, impresa y reproducción digital de diversos códices prehispánicos y coloniales resguardados en la Biblioteca del Instituto Nacional de Antropología e Historia; fotografías de ejemplares de asientos y sus fichas de datación y catalogación, que se encuentran en el repositorio del Instituto Nacional de Antropología e Historia, (Mediateca) y los ejemplares físicos resguardados en los museos Nacional de Antropología y de Arte Moderno en la Ciudad de México, Museo "El Palacio" en Campeche, Gran Museo del Mundo Maya en Mérida, Museo Universitario Rangel Hidalgo en Nogueras, Colima, Museo de Filadelfia, y el Museo Metropolitano en la ciudad de Nueva York, en los Estados Unidos de América, recuperados del catálogo digital de cada uno.

La observación y el análisis comparativo de los datos contenidos en la serie de documentos obtenidos, libros y las publicaciones especializadas de investigaciones previas, fue el método utilizado en este trabajo, como parte de una investigación más extensa sobre la historia y desarrollo del mueble mexicano.

\section{El butaque}

El butaque toma su nombre de la palabra "butaca", tropicalizada al francés o creole de la Luisiana, también se le conoce como silla Campeche, puesto que desde la ciudad y puerto de Campeche, se exportaba a diferentes latitudes, incluso a España peninsular. Es un asiento de descanso de manufactura artesanal elaborados con madera de pino los más rústicos y las más elaboradas, de maderas preciosas presentes en cada región.

Su estructura lateral está constituida por dos largueros ensamblados por caja, asimétricamente entre sí, formando una X en la que el elemento más largo conforma el respaldo; en la parte inferior, unos sencillos bastones de madera torneada, sirven como armadores. La continuidad del asiento y respaldo, así como el perfil que forman los dos largueros cruzados son los rasgos que le distinguen de otros tipos de asientos, sumado a la inclinación que se logra, hacen de este un mueble sumamente cómodo, destinado para el descanso.

El ejemplar más antiguo que se conoce, es el que forma parte de la colección del Museo de Filadelfia ${ }^{4}$, manufacturada en caoba con tapicería de cuero cincelado y claveteado con bronce y que según su catalogación, data de entre 1730-1770, por la cresta en forma de arco ondulado y tallada con una concha de vieira, frecuentemente utilizada como motivo decorativo de los muebles del periodo barroco en México. 
El butaque fue también un asiento muy utilizado en las casas de las plantaciones en el estado de Luisiana ${ }^{5}$, en los Estados Unidos de América, mercado al que llegó primeramente, por el comercio que se tuvo con la Nueva España, específicamente entre el puerto de Campeche y la ciudad de Nueva Orleans, que hasta 1800 fue territorio español, pero con una gran población francófona ${ }^{6}$; expandiendo su uso hasta los estados del Sur de aquél país, y debido a la demanda por los señores de las plantaciones, se reprodujeron algunos ejemplares con mano de obra de los esclavos. El entonces presidente de los recién formados Estados Unidos de Norteamérica, Thomas Jefferson (1801-1809), tuvo varios ejemplares en su residencia Monticello, en el estado de Virginia, y en sus cartas denotaba el apego emocional que tenía hacia un ejemplar en particular, y daba cuenta de su comodidad. En la actualidad se desconoce el paradero de esta silla en particular, pero en el Museo James Madison en Orange, Virginia, se exhiben ejemplares tanto de procedencia mexicana como estadounidense, distinguiéndose en la talla del copete y el cuero cincelado de la tapicería claveteada que presentan los ejemplares mexicanos.

En México, el Centro Cultural El Palacio en la ciudad de Campeche,en la sala dedicada al comercio exhiben 3 ejemplares de butaques, uno con brazos en voluta y dos sin brazos, los tres ejemplares presentan tapizados en piel claveteada al marco, como parte de las manufacturas que se comercializaban, e incluso se exportaban desde este puerto, a Veracruz y desde ahí a destinos como La Habana, Cádiz, Málaga ${ }^{7}$ y Nueva Orleans, como consta en el manifiesto de carga de la embarcación "Jenny”, documentada en Campeche con fecha de abril de 1808 , en la que se declaran 4 butaques. $^{8}$
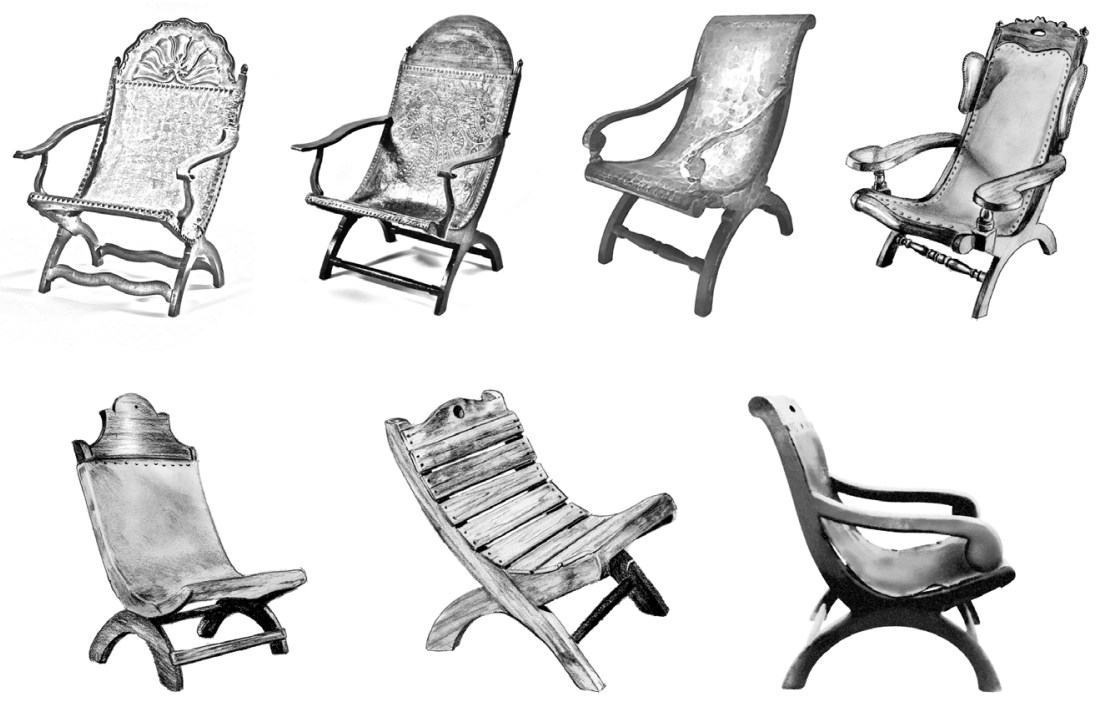

Ilustración 1. Butaques Siglos XVII al XIX. Sup. Izquierda a derecha: A. Butaca, 1730-1770, Museo de Filadelfia, Pensilvania, catálogo digital, inv. 2012-178-1, https://philamuseum.org/collections/ permanent/313148.html, dibujo de: AMTR. B. Silla Campeche, ca. 1820, Museo James Madison, Orange, Virginia, catálogo digital, https://www.thejamesmadisonmuseum.net/exhibits?lightbox=dataItem-if1a9rtn, dibujo de: AJRT; c. Butaque S. XIX, Gran Museo del Mundo Maya de Mérida, Yucatán, fotografía: MHP, dibujo de AMTR; d. Silla Campeche, S. XVIII, Museo de Arte Colonial, La Habana, sd. Cuba, fotografía MHP, dibujo de: JRRT; Abajo: e. Butaque con piel de venado, S. XIX, procedencia de Yucatán, recuperada de: https://donshoemaker.com/what-is-the-difference-between-a-mexican-campeche-chair-and-a-butaquepart-2/\#jp-carousel-5797, dibujo JRRT; f. Butaque popular de la región de Tehuantepec, Oax. S. XX, Sala 18 de etnografía, Museo Nacional de Antropología, fotografía: MHP, dibujo de JRRT; g. Butaque, S. XIX, Centro Cultural "El Palacio", Campeche, Campeche, s/d, fotografía: MHP, dibujo JAIJ. 
En el Gran Museo Maya, se tiene en exhibición un butaque sencillo, sin brazos, como parte de los bienes que se comercializaban y exportaban de la Capitanía de Yucatán, así como un butaque elaborado en madera más fina, con brazos y travesaños torneados, tapizado con piel claveteada al marco.

Del origen del butaque o silla campechana, existe poca información; suponemos que surgió posiblemente entre finales del siglo XVI y principios del XVII, como resultado del intercambio cultural, ya que los pueblos americanos no ejercían los oficios de la carpintería y ebanistería, sino que estos fueron trasplantados desde Europa y difundidos posteriormente a la Conquista.

Son pocos los especialistas del mueble mexicano que han mencionado al butaque; Ana Elena Mallet, en su libro Silla Mexicana ${ }^{9}$ hace un exhaustivo inventario de los asientos mexicanos del siglo XX, e incluye un apartado al butaque en el que Jorge Rivas Pérez atribuye el origen de la silla campechana a un asiento ceremonial utilizado por los pueblos tahinos del caribe, denominados "duhos", por la similitud en el perfil curvo que forman el asiento y el respaldo alto de estos últimos, de los que se deriva el asiento llamado "ture" ${ }^{10}$, y que fue, producto de la adaptación de un asiento autóctono, con la tecnología europea del Siglo XVI; asimismo, afirma que fue llevado desde Venezuela a la Nueva España ${ }^{11}$. Si bien hay similitudes, los armadores del asiento ture son completamente rectos, mientras que en el butaque son curvilíneos y forman dos medios círculos, por lo que son más confortables, más allá de la armonía y equilibrio del conjunto.

Por su parte, Cybèle Trione Gontar ${ }^{12}$, en su análisis de la silla Campeche, atribuye su origen a una evolución del asiento curul romano, que también presenta un perfil en forma de "X", en su vista frontal, al igual que la jamuga, de caderas, la dantesca y la savoranola o florentina, y en algunos casos permiten plegarse, puesto que el cruce de ambos soportes forma un eje que permite ese movimiento, y tanto el asiento como el respaldo son de material flexible, cuero o textil, lo que facilita su portabilidad.

Teresa Castello de Yturbide en Artes de México ${ }^{13}$, describe las variantes regionales del butaque en Jalisco, Campeche, Yucatán, Oaxaca, los clasifica como mueble popular.

Abelardo Carrillo y Gariel ${ }^{14}$, hace un muy breve comentario al atribuir su origen español, por la semejanza con la silla jamuga o de caderas, ya que en algunos códices coloniales, como en las láminas del Lienzo de Tlaxcala, se representan varios personajes españoles, sobre asientos con la característica " $X$ " de forma lateral y no frontal, como en la silla de caderas.

Partiendo de este último y buscando las fuentes primarias que menciona, surgieron las interrogantes de ¿cuál es ese asiento presente en los códices coloniales?, ¿si se trataba de la misma silla de caderas o de otro tipo de asiento? si se deriva de la silla de caderas, ¿cómo fue esa transformación? y finalmente, si ¿es una apropiación de formas y usos de mobiliario europeo? $\mathrm{O}$ ¿es un asiento original del territorio mexicano? De ser así, entonces el butaque tendría los atributos suficientes para representar al mueble mexicano del siglo XX. Para responder a lo anterior, se recurrió a publicaciones que traten del origen del mueble en México, más precisamente el mueble europeo, y la forma en que se adoptó durante el siglo XVI en la sociedad. 


\section{Arribo de asientos europeos a México}

Los asientos de origen español o europeo, que se tienen documentados en el siglo XVI, fueron de dos tipos, la silla francesa o imperial y la silla de caderas. Ambos tipos de asiento se mencionan tanto en las Ordenanzas de Carpinteros y entalladores como en los diversos inventarios de casas y palacios.

Dichas Ordenanzas fueron dadas por el cabildo de la Ciudad de México y aprobadas por los virreyes el 30 de agosto de 1568, y confirmadas por la Real Audiencia Gobernadora el 26 de octubre del mismo año. En estas, además de garantizar la calidad de lo que se compraba, menciona como requisito para tener tienda que se le examinara al entallador que supiera hacer un escritorio con sus tapas y bases de molduras y arquitrabe y cornisas, una cama de campo torneada, una mesa de seis piezas, una silla francesa, otra de caderas ataraceada. ${ }^{15}$

Respecto a los asientos, la francesa se distingue por una estructura recta y rígida, con un respaldo alto formado por la típica arquería del renacimiento con barrotes torneados o simplemente por terciopelo brocado sujeto a los barrotes, con asiento de vaqueta claveteada o de la misma tela gruesa, que sirvió como inspiración a estilos posteriores; este tipo de sillas también se conoce como "fraileras", puesto que fue bastante frecuente su uso en los conventos, aunque posteriormente se le agregaron tallas, brazos, y tapizado con textiles más lujosos; la estructura de líneas y ángulos rectos, tanto de frente como lateral es su aspecto distintivo. (Ilustración 2).
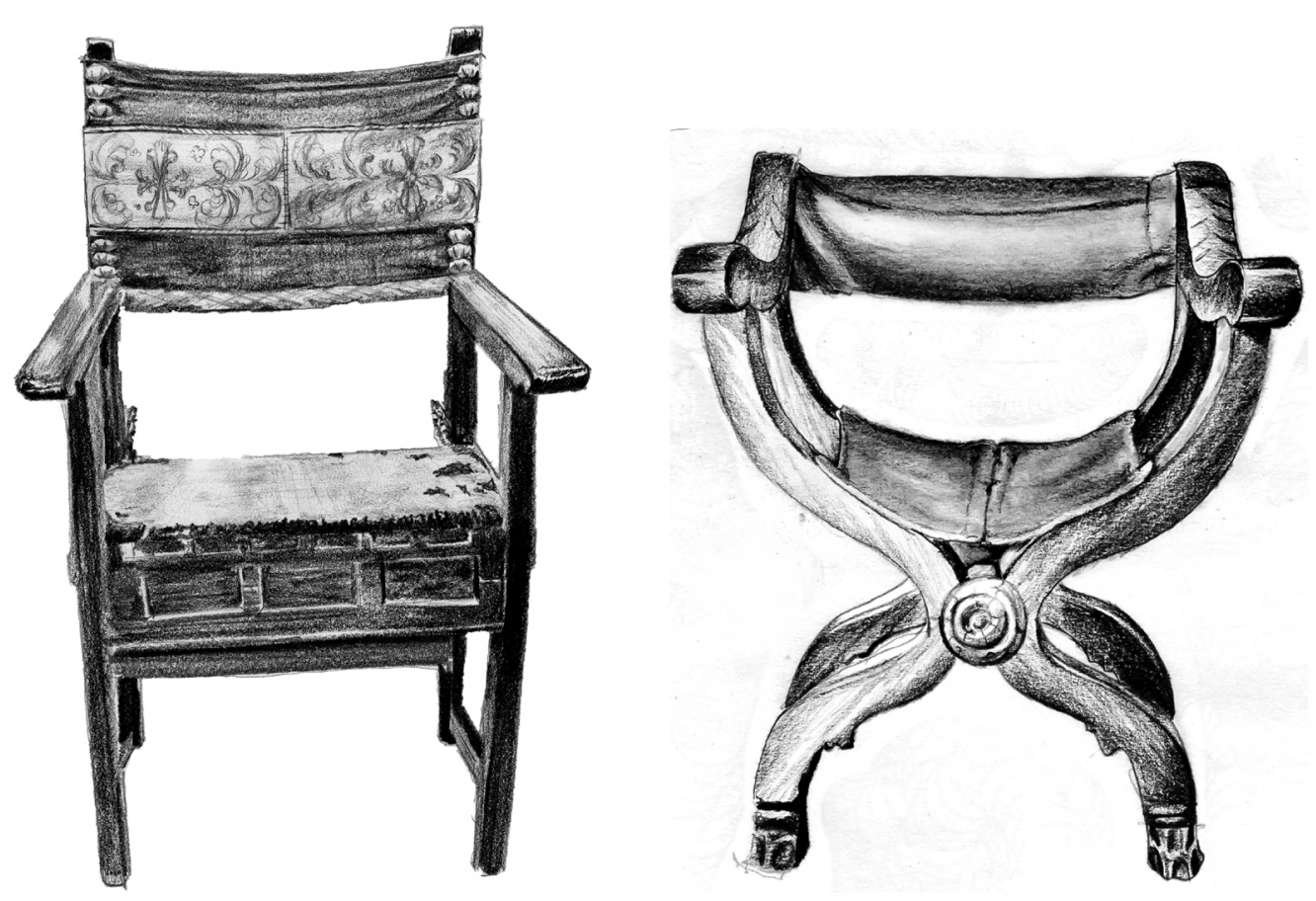

Ilustración 2. Ejemplos de tipos de asientos de origen europeo utilizados durante el siglo XVI en México: izq. Silla Francesa con brazos de madera y terciopelo al aire para asiento y respaldo, fijos por medio de clavos ovoidales, respaldo con bordado, chambrana delantero, de manufactura española; ca. 1501-1600, MNAD, Madrid, catálogo digital, inv:CE00529, http://ceres.mcu.es/ pages/Main. Der. Silla de caderas o jamuga, madera tallada y asiento de cuero cosido, S. XVI, Museo Regional Cuauhnáhuac, Cuernavaca Mor., fotografía: MHP. Dibujos de: JRR. 


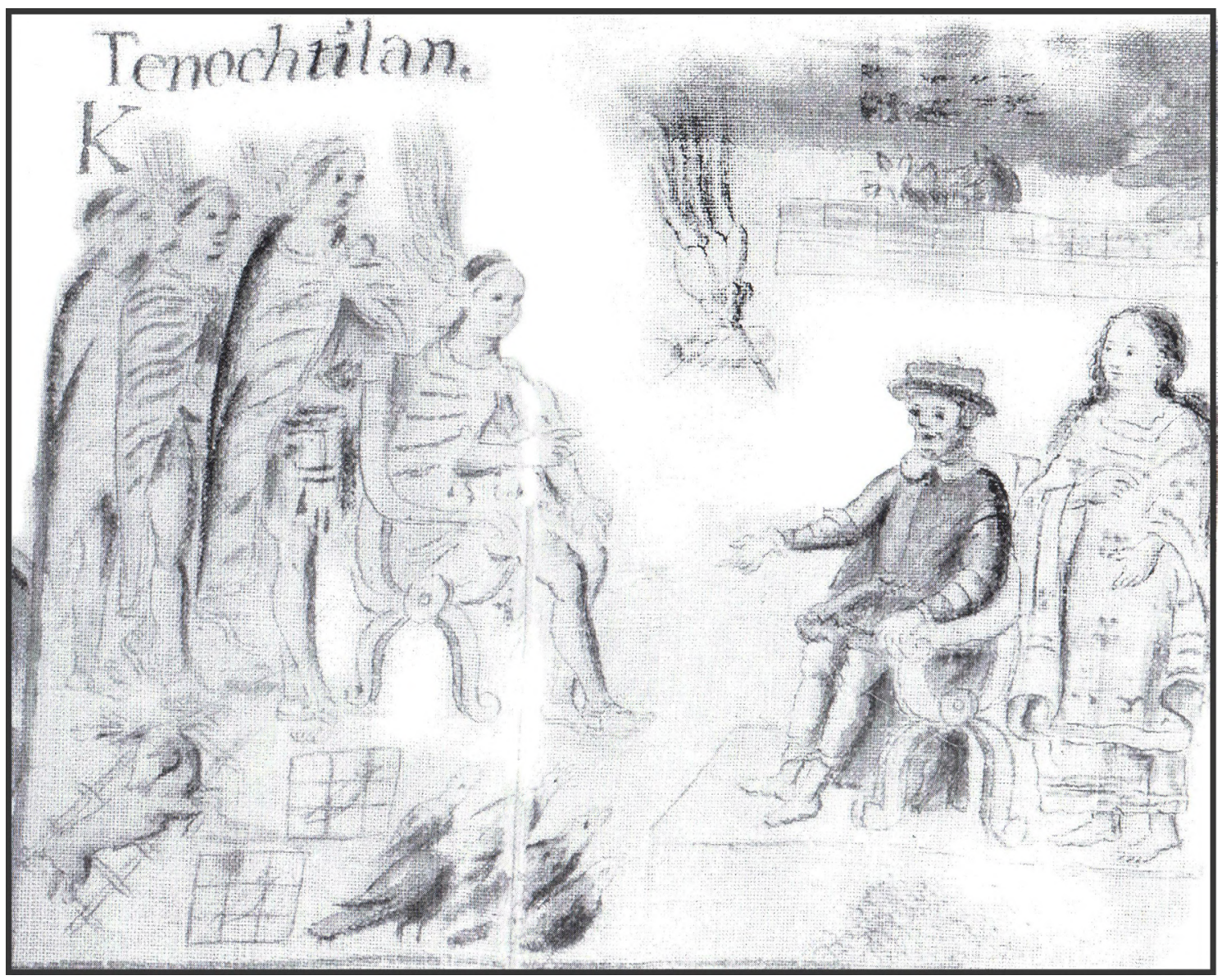

Ilustración 3. Recuadro K del Lienzo de Tlaxcala, S. XVI, copia del año 1773. Códices de México, INAH., recuperado de: https://www.codices.inah.gob.mx/movil/contenido.php?id=50: dibujo de JAIJ.

En cambio, la silla de caderas, también conocida como florentina, dantesca o jamuga, es un asiento de doble tijera que permite ser plegada. Está formada por cuatro montantes curvos en forma de "ese" que se articulan por parejas cuyo punto de intersección, recortado en forma circular, se decoraba con labor de taracea de motivos geométricos, y permite el medio giro para posibilitar el plegado; ambos se unían por medio de dos zapatas en la base, dos travesaños en los cuales se afirmaba el asiento y dos brazos curvos que se alzan para recibir el respaldo. El asiento y respaldo estaban elaborados en cuero, simple o repujado algunos, también con terciopelo bordado y galones dorados otros, que además de su propia función de soportar el cuerpo, evitaban que la silla se abriera más de lo conveniente.

La silla de caderas decorada con taraceas está ampliamente documentada por los cronistas de la conquista, como Bernal Díaz del Castillo, en la Historia Verdadera de la Conquista de la Nueva España ${ }^{16}$, al describir los regalos que Cortés envió a Moctezuma con Tendile:

"Y luego Cortés mandó traer una silla de caderas, con entalladuras muy pintadas..."

Y en seguida escribe: 
“...que luego enviase aquella silla en que se asiente el Señor Montezuma, para quando le vaya á ver y hablar Cortés"

Desde ese histórico encuentro entre Hernán Cortés y Moctezuma, se relacionó a la silla de caderas como un asiento de poder, reservado para el personaje de mayor jerarquía ${ }^{17}$. Dicha escena quedó registrada en el recuadro marcado con la letra K en la segunda línea del lienzo de Tlaxcala elaborado en el S. XVI, (ver ilustración 3); el mismo Hernán Cortés es representado siempre sentado en él, así como los españoles, frailes y encomenderos.

\section{Los códices mexicanos y el lenguaje pictográfico}

Los códices (del latín codex, que significa "libro manuscrito") ${ }^{18}$ son los documentos pictóricos o de imágenes que fueron realizados por las culturas indígenas de México ${ }^{19}$ y América Central, y en ellos registraban sus conocimientos y proporcionan información sobre su historia, antes de la llegada de los españoles y aún después de la conquista, ya que se la producción continuó llevándose a cabo hasta el siglo XVIII. En la actualidad se consideran como fuentes históricas de primera mano, puesto que, más allá de ser una de sus manifestaciones artísticas, dejaron testimonio de la visión indígena, plasmada en su sistema de escritura, y como tal, la información que proporcionan estos documentos es tan valiosa, como las crónicas y demás escritos de los conquistadores y frailes españoles del siglo XVI.
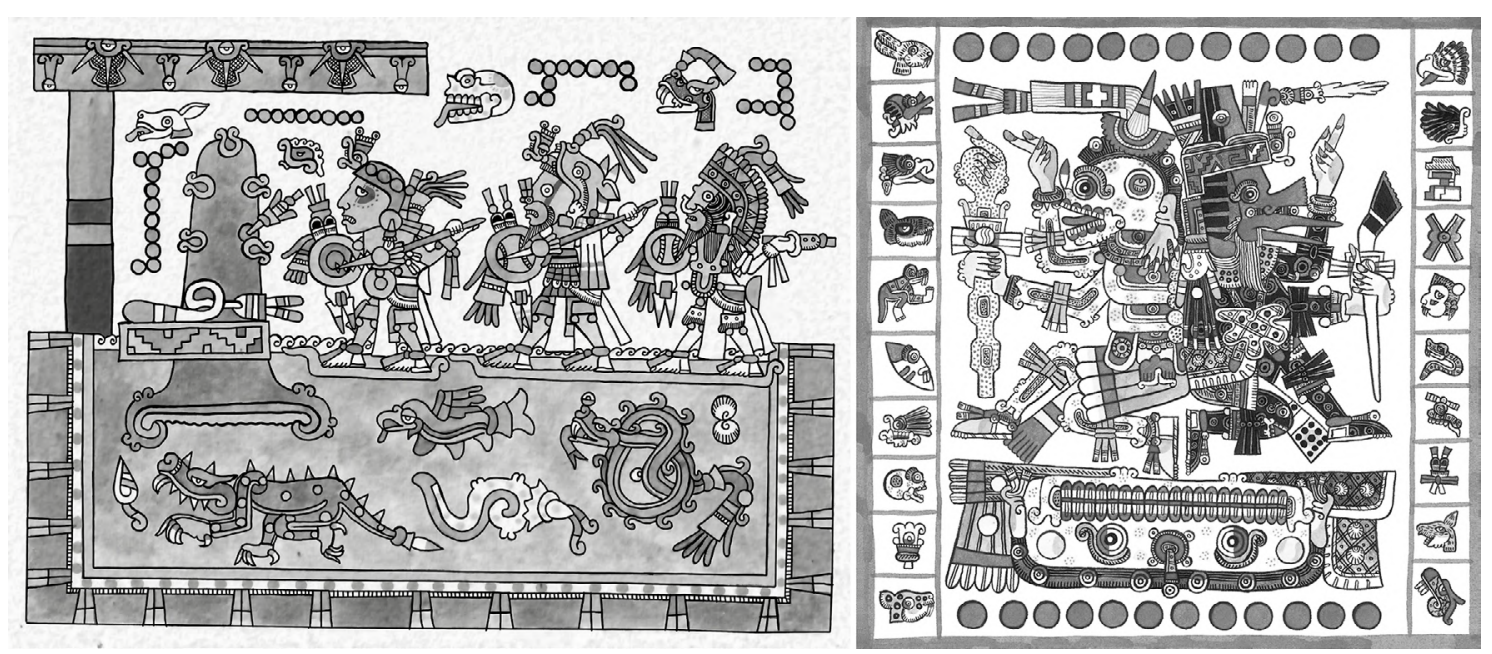

Ilustración 4. Códices prehispánicos: Izq, Lámina 80 del Códice Nutall, dibujo: Lacambalam, recuperado de: https://commons.wikimedia.org/wiki/File:Lámina_del_Códice_Nuttall.jpg; derecha: lámina 73 Códice Borgia, tomada del Díaz Gisele, y Rodgers ala, The Codex Borgia, p. 5.

El lenguaje que utilizaban para su elaboración era el pictográfico, que se caracteriza por plasmar de manera estilizada, la mayor cantidad de detalles en cada uno de los ideogramas, personajes y escenas, por lo que la gran mayoría de personajes, objetos, animales, etc., se representaban de perfil, de esta forma las 
características fisiológicas del rostro, la indumentaria, los adornos corporales, podían plasmarse más detalladamente. El torso, igual podía presentarse de perfil, pero en algunos casos, las piernas y pies se representaban separadas. En la mayoría de los códices prehispánicos se encuentran estas características, aunque cada región tenía su propio estilo y código estético, de ahí que se clasificaron de acuerdo a la región o etnia que lo produjo, códices mixtecos, mexicas y mayas. (Ilustración 4)

Fue en las escuelas fundadas por los frailes, como la Escuela de Artes Oficios de Fray Pedro de Gante, en el Convento de San Francisco en la ciudad de México $^{20}$, que las técnicas renacentistas de pintura, como la perspectiva axonométrica, fueron enseñadas a los naturales, así también la composición figurativa realista, contraponiéndose en algunos casos, a la estilización abstracta de las técnicas pictográficas indígenas. Estas nuevas maneras de representar la realidad, pueden verse plasmadas en los frescos de los murales de los conventos e iglesias franciscanos y agustinos diseminados por el centro del país.

Así también los acontecimientos importantes debían ser registrados en la lengua y a la manera indígena de hacerlo para darle validez jurídica, por lo que surgen los llamados códices coloniales. En estos documentos, la técnica pictográfica hicieron posible su conservación; el mismo Fray Pedro de Gante recurrió a esta para crear el catecismo y algunas oraciones para facilitar su memorización entre la población indígena; Fray Bernardino de Sahagún con la ayuda de un tlacuilo, también utilizó este lenguaje pictográfico en la elaboración del Códice Florentino (1540-1585), al que el fraile le escribía en castellano la traducción, ejemplar que posteriormente fue publicado como la "Historia General de las Cosas de la Nueva España”.

Otro ejemplo de estos códices es el Lienzo de Tlaxcala elaborado entre 1535 y 1550, se documentan la estructura política de esta población, así como algunos eventos importantes en que los tlaxcaltecas acompañaron a los conquistadores y los privilegios que recibieron algunos caciques indígenas por esa alianza; estos códices se consideran como mixtos, puesto que si bien conservan el estilo y la forma pictográfica de los tlacuilos, se incorporan elementos de la convención europea, como la forma casi realista de representar a los personajes y objetos, y en algunos hay frases en castellano combinadas con los pictogramas. ${ }^{21}$

En dichos códices coloniales, es posible observar entre otras cosas, el mobiliario de origen español que utilizaban, sobre todo frailes y conquistadores, como bancos, escritorios y sillas de cadera, como en el Códice Cuetlaxcohuapan. En los códices elaborados durante el siglo XVI y, en los que se representan personajes españoles, aparece el mismo tipo de asiento, como en el Códice o Tira de Tlatelolco, elaborado en 1562, y abarca una secuencia histórica de 1542 a $1560^{22}$, en la lámina 1 se representa a un personaje indígena, probablemente Diego de Mendoza Imauhyantzin, Cacique de Tlatelolco, sentado en una silla de caderas, claramente definida bajo el sistema de perspectiva axonométrica, pero difícil de reinterpretar como tal si el lector no está familiarizado con el asiento y con el sistema axonométrico. (Ilustración 5)

A diferencia, por ejemplo, en el Códice de San Juan Teotihuacán, fechado a mediados del Siglo XVI, los frailes aparecen sentados en otro tipo de asientos, 
muy similares a la silla de caderas, solo que los montantes que forman la "X" se encuentran en los costados; en el Códice Yanhuitlán elaborado en 1544, aparecen el encomendero y su hermano, sentados en unas sillas parecidas a las anteriormente descritas, aunque el dibujo se elaboró con más detalle, denotando mayor influencia europea en el trazo. En el códice Huejotzingo fechado en el año de 1568, aparecen en dos de sus láminas, el corregidor sentado en el mismo tipo de asiento. (Ilustración 6).

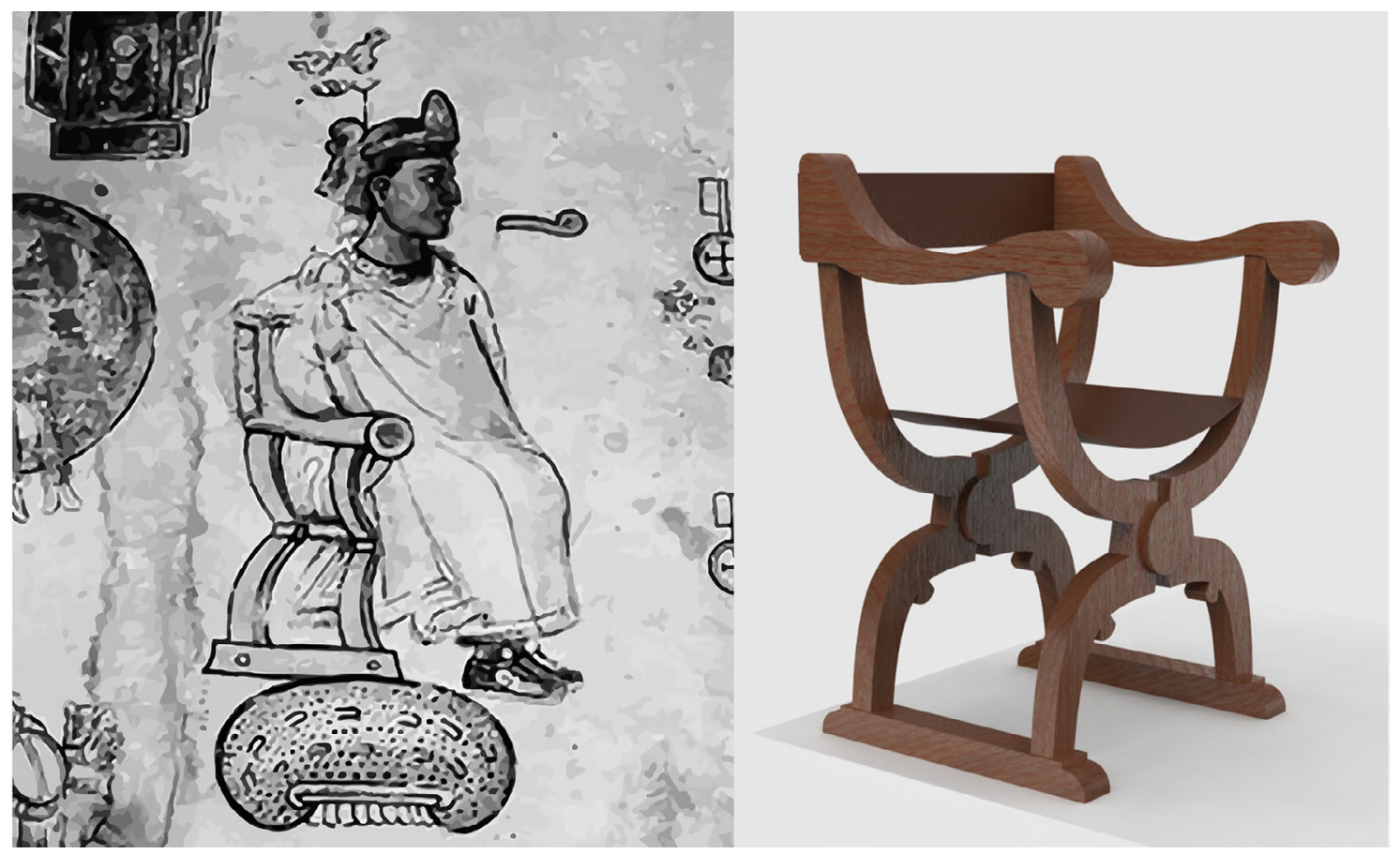

Ilustración 5. Izq. Detalle de la lámina 1 de la Tira de Tlatelolco representando al cacique sentado en una silla de caderas, ca. 1562; original se encuentra en la Biblioteca Nacional de Antropología e Historia, sig. 35-39; recuperada de Mediateca INAH, https://mediateca.inah.gob.mx/repositorio/islandora/object/ fotografia:281368; Der. Dibujo de una silla de caderas. Autor: AAR.

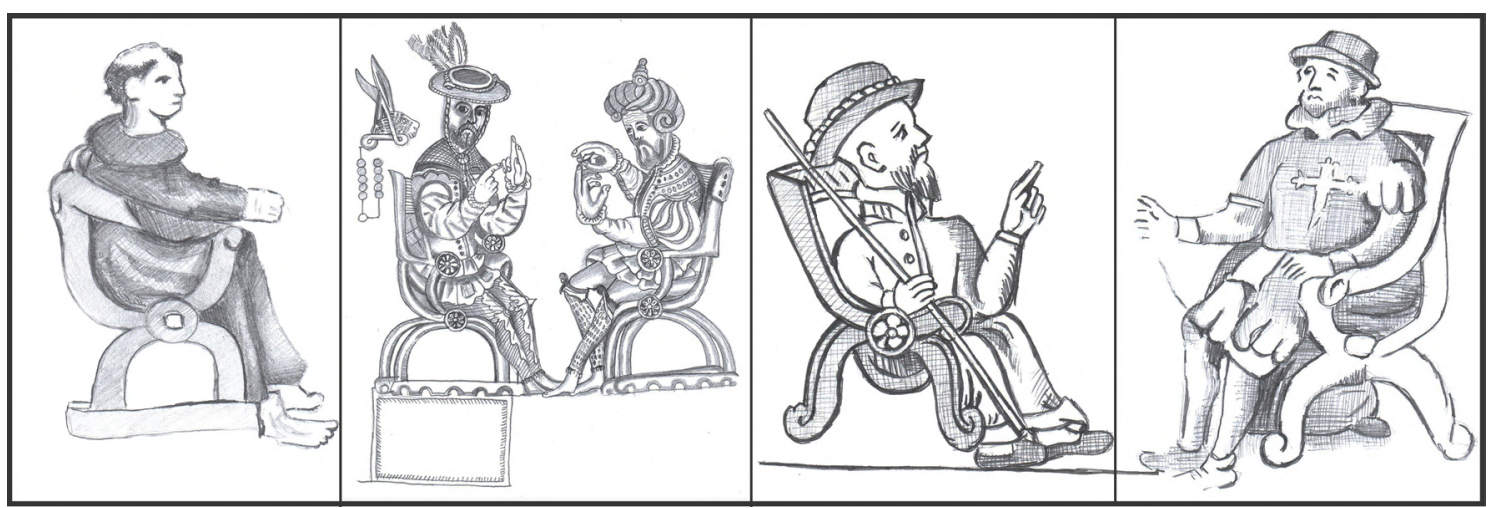

Ilustración 6. Códices Coloniales: Detalle de la Tira de San Juan Teotihuacán, S. XVI, original se encuentra en la BNAH Dr.Eusebio Dávalos Hurtado; Lámina del Códice de Yanhuitlán, 1544, reprografía. I.O. "CXLVIII-99, Fototeca Nacional, recuperado de: Mediateca INAH; Detalle de la lámina 1AA del Códice de Huejotzingo, S. XVI, original en la BNAH. Detalle de la tira de Tlaxcala, S. XVI, Copia realizada por José Manuel Yllañez en 1773, resguardada en la BNAH, recuperado de https:// www.codices.inah.gob.mx/movil/contenido.php?id=50. Dibujos: JAI 
En el documento conocido como el Lienzo de Tlaxcala, elaborado entre los años 1535-155023, que fue encargado por las autoridades civiles con el objetivo de demostrar a la corona española las alianzas que hicieron con el capitán Hernán Cortés para someter a los Mexicas; y en este se presentan elementos tanto de origen prehispánico como europeo; en la parte inferior se representan 87 pequeñas escenas que abordan diversos temas como la llegada de los españoles, las alianzas que hicieron con los tlaxcaltecas, la conquista en sus diferentes fases, la matanza de Cholula y la derrota de Cuauhtémoc; en la parte superior se presenta la estructura política de Tlaxcala, con 13 personajes españoles sobre asientos que presentan en su perfil lateral, una forma de X.

Manuel Toussaint, refiriéndose a este Lienzo, afirma que se trata “... de la silla florentina plegadiza, que forma hacia la parte de abajo un ángulo curvilíneo, el cual se repite hacia arriba para hacer el asiento..."; solo que está representada de frente y se colocaban los brazos como si estuviese de perfil, y atribuye esto a la torpeza del tlacuilo. ${ }^{24}$

Tomando en cuenta que el lenguaje pictográfico del tlacuilo, que tomaba las características más predominantes de los objetos en las escenas que pintaba, se deduce que se trata de la silla de caderas por la posición de los montantes, y por ser el asiento español mayormente usado en el siglo XVI. En estos documentos, el asiento que representan en las escenas, presenta la particularidad de los montantes en X ubicados en los laterales, según la interpretación actual del dibujo técnico y la perspectiva axonométrica, se encontrarían en las vistas laterales del producto; se representa también el rosetón que marca la intersección de ambos montantes, así como la zapata que une los soportes anteriores y posteriores, que impediría el plegado o la "tijera". (Ilustración 7).

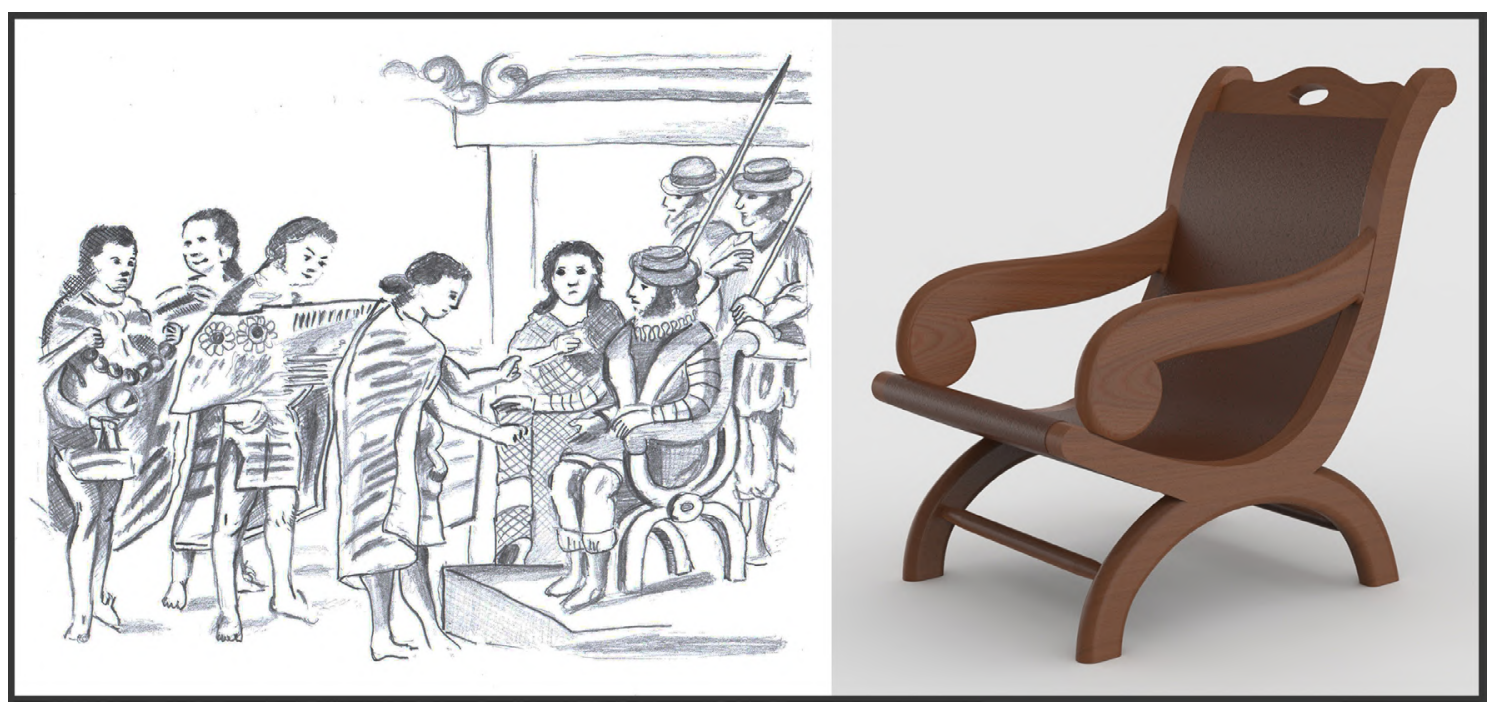

Ilustración 7. Detalle de la Tira de Tlaxcala, recuadro C, S. XVI, copia realizada por José Manuel Yllañez en 1773, resguardada en la BNAH, recuperado de https://www.codices.inah.gob.mx/movil/ contenido.php?id=51 Calca del original, elaborado por José Antonio Ibarra; Original: Mediateca INAH. Derecha, dibujo digital de butaque, elaborado por AAR 
$\mathrm{Al}$ observar los ejemplares más antiguos de butaques, es notoria la referencia del perfil de esta con las representaciones de las sillas en los códices coloniales, pero aún más en los ejemplares de butaque elaborados por los grupos indígenas en la región del Golfo y en la península de Yucatán en los siglos XIX y XX, en los que es más evidente dicha semejanza. Entonces es posible que en generaciones posteriores, los carpinteros y artesanos indígenas, que ya habían asimilado el sistema renacentista del lenguaje gráfico y su interpretación, y si las únicas referencias para la elaboración de muebles fuesen los códices coloniales, el resultado de esa relectura bajo los cánones europeos, diera como resultado el butaque. Al comparar los pictogramas, sobre todo de la Tira de Tlaxcala, con los butaques más rústicos, que se conservan en el Centro Cultural El Palacio, en la ciudad de Campeche, y en el Gran Museo del Mundo Maya de Mérida, es notable la semejanza de ambos asientos, como si la representación pictográfica del siglo XVI hubiera servido como referencia para la construcción de los butaques, con pequeñas diferencias en cuanto a elementos que le otorgaran mayor estabilidad.

A partir de la popularidad del butaque, y paralelamente con el desarrollo tecnológico y técnico, el artista estuvo en condiciones de reinterpretarla según sus propias habilidades y algunas adaptaciones de acuerdo al mercado objetivo para el que fuera elaborada, por lo que aparecen variables con brazos ondulados, diversidad de remates tallados o con incrustados (taracea y/o marquetería), travesaños torneados, tapicería de cuero simple, pintado o cincelado, los más costosos, tejidos de bejuco, etc., y los más rústicos, fueron elaborados con listón de madera, unidos a canto para darle la curvatura que marcara el marco o sin brazos.

\section{Conclusiones}

Tanto Toussaint (1948), como Carrillo (1957) notaron la diferencia entre la silla jamuga o de caderas y el asiento representado en los códices del siglo XVI: la posición del medio arco que forman los soportes inferiores de forma lateral en esta última, y no frontal como corresponde a la primera. Ambos autores coinciden que se trata de otro tipo de asiento y que, además de estos códices, no está documentado en crónicas ni inventarios, pero no lo comparan con el butaque, probablemente, porque es un asiento que entonces era más conocido fuera de la Ciudad de México.

Si, como anteriormente se expuso, el butaque surgió en el siglo XVII de la relectura de los códices coloniales de un siglo anterior, y su producción y uso se extendió en la población predominantemente indígena y rural mestiza, que adaptaron la forma con materiales disponibles en cada región, a través del tiempo se ganó el atributo de vernáculo.

En el siglo XX los arquitectos y diseñadores, siguiendo la filosofía estética de Vasconcelos, para la difusión de la identidad cultural mexicana a través del arte nacionalista post revolucionario en todas sus expresiones, y que su obra fue reconocida a nivel nacional e internacional, fue entonces que el butaque cobró importancia, puesto que tomaron un mueble de tradición y uso rural, que al reproducirlos y reinterpretarlos de muchas formas, con diversos materiales, 
técnicas y acabados de mejor calidad, dejaron su carácter provinciano y popular para insertarlos en las residencias de los círculos intelectuales afines a la "alta sociedad"; con esta nueva categoría, se fijó en el imaginario colectivo trascendiendo a lo largo del siglo XX, lo que le otorgó el valor de arquetipo del mueble mexicano moderno.

El Dr. Rivas fundamenta el origen del butaque en la reinterpretación del asiento ceremonial duho, y su difusión desde Venezuela; la hipótesis aquí presentada, presenta la posibilidad del origen en la relectura de los códices coloniales mexicanos, que originalmente fueron elaborados en el lenguaje pictográfico resultante de la combinación prehispánica y renacentista de representar la realidad, y la reinterpretación de esta bajo un sistema y normas diferentes. Sin embargo, por distintas que puedan ser las posturas, se coincide que el butaque es producto, al igual que la cultura latinoamericana, de la combinación de tradiciones y saberes de ambos continentes.
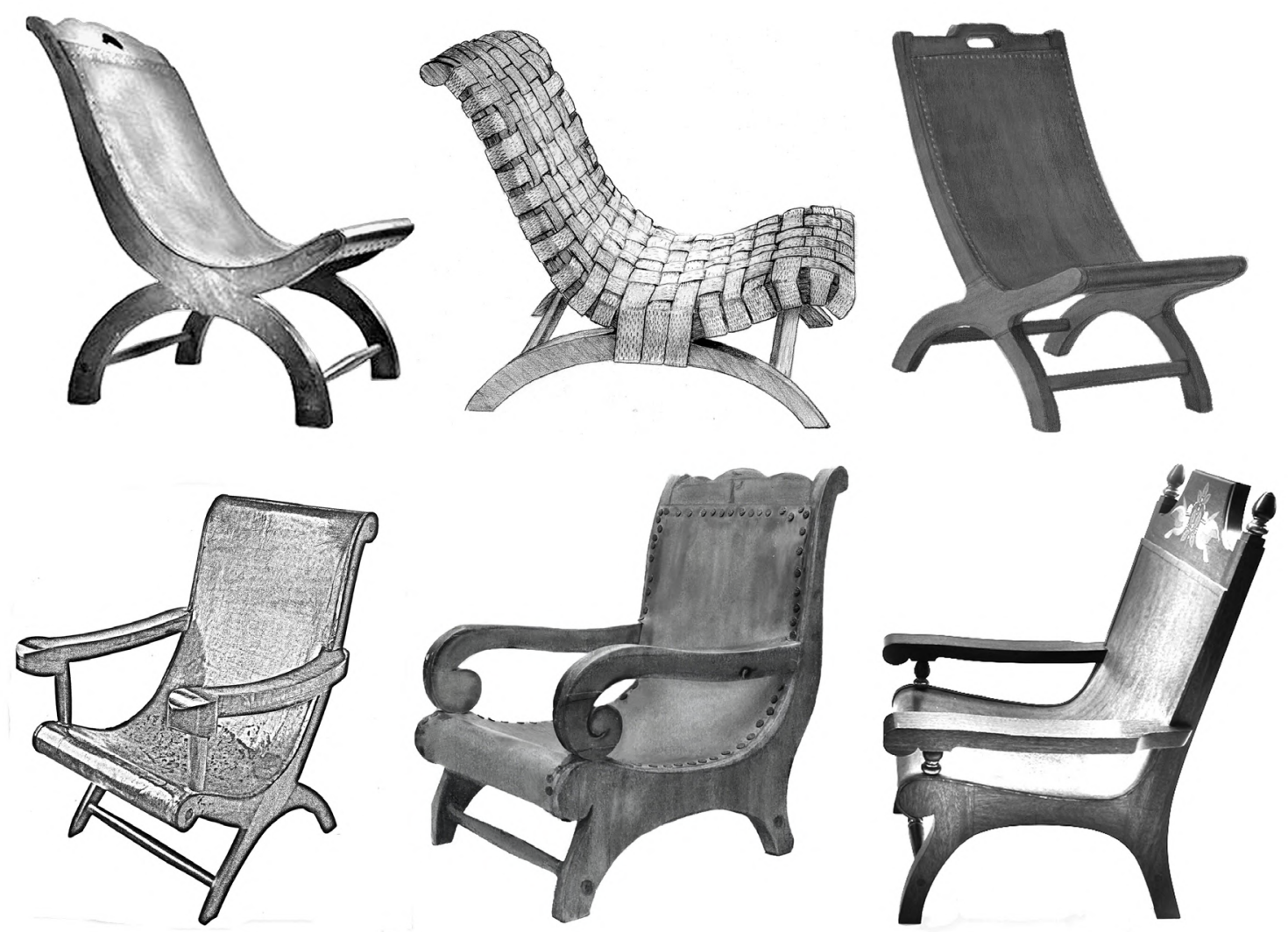

Ilustración 8. Butaques de autor: superior de izquierda a derecha : William Spratling, Ca. 1935, recuperada de: https://donshoemaker.com/the-revival-of-the-butaque-chair-in-mexican-20th-centuryfurniture-design-part-3/\#jp-carousel-5817, dibujo: JAGC; Butaque madera de sabino y tejido de yute, Clara Porset, ca.1950, col DI Jorge Enrique Yañez, fotografía: Guillermo Soto, Tomado de: El Diseño de Clara Porset, Co Ed. UNAM, Franz Mayer CIDI, p. 124, dibujo de: JRRT; Josef Albers, 1940, Col. Privada, fotografía recuperada de: https://www.sothebys.com/en/auctions/ecatalogue/2017/importantdesign-n09650/lot.41.html, dibujo de: MATA; inferior: Luis Barragán, 1947, col. MAM Ciudad de México, fotografía: MJHP, dibujo de: AJRT Manuel Parra, ca. 1950, colección privada, fotografía recuperada de ADN Galería.com, el 24-09-2019, dibujo de: MATA; Alejandro Rangel Hidalgo, 19651970, Museo Universitario Alejandro Rangel Hidalgo, Nogueras, Col., fotografía: MHP, dibujo de: AJRT. 


\section{NOTAS}

${ }^{1}$ Martha Cecilia Calderón Pichardo, "José Vasconcelos. Diferencia y continuidad del proyecto de nación," Revista Digital Universitaria (RDU) 19, no.5 (2018), 4, doi: http://doi.org/10.22201/ codeic.16076079e.2018.v19n5.a8.

${ }^{2}$ Gerardo Murillo, Las artes populares en México (México: Instituto Nacional Indigenista, 1921).

${ }^{3}$ Marion Jr. Oettinger, Tesoros del arte popular mexicano, colección de Nelson A. Rockefeller, (México: Ed. Artes de México, 2009), 13.

${ }^{4} \mathrm{https}: / /$ www.philamuseum.org/collections/permanent/313148 html?mulR=2113741750 | 1

${ }^{5}$ Cybèle Trione Gontar, "The Campehe Chair in The Metropolitan Museum of Art," Metropolitan

Museum Journal 38, (2003), 183.

${ }^{6}$ La Luisiana Francesa fue declarada territorio Francés a finales del Siglo XVII; Después de la guerra de los 7 Años, por el Tratado de París éste fue cedido a España en 1763; En 1800 Francia adquiere de nueva cuenta, gracias al Tratado de San Ildefonso, y finalmente, lo vende a los Estados Unidos de América en 1803. Manuel Trillo, "Cuando España dominaba las gigantescas Texas y Luisiana con un puñado de hombres," $A B C, 17$ de junio, 2018, s.p..

${ }^{7}$ Jorge Rivas Pérez, "Butacas y butaques: sillas nuevas para el Nuevo Mundo," en Silla mexicana, ed. Ana Elena Mallet, (México: Arquine, 2017), 34

${ }^{8}$ Trione Gontar, "The Campeche..”, 184

${ }^{9}$ Ana Elena Mallet, Silla mexicana (México: Ed. Arquine, 2017).

${ }^{10}$ Jorge Rivas Pérez, "Observaciones sobre el origen del origen y manufactura del mobiliario en América Latina," en Revelaciones, las artes en América Latina 1492 -1820. (México: Fondo de Cultura Económica, 2007), 486.

${ }^{11}$ Rivas Pérez, "Butacas y butaques", 31

${ }^{12}$ Trione Gontar, "The Campeche..", 190

${ }^{13}$ Teresa Castello De Yturbe, "El mueble popular," El Mueble Mexicano XVI, no. 118 (1969): 81.

${ }^{14}$ Abelardo Carrillo y Gariel, Evolución del mueble en México. (México: Dirección de Monumentos Coloniales, INAH, 1957), 41.

${ }^{15}$ Antonio Francisco Garabana, "El mueble del sigo XVI y su origen español," El Mueble Mexicano XVI, no. 118 (1969): 11.

${ }^{16}$ Bernal Díaz del Castillo, Historia Verdadera de la Conquista de la Nueva España. (Madrid: Ed. Benito Cano, 1795), 106.

${ }^{17}$ En las culturas mesoamericanas se utilizaron muchos tipos de asientos, pero solo el Huey Tlatoani o emperador, utilizaba exclusivamente el Icpalli, una siento más alto y elaborado que los otros, por lo que desde antes de la llegada de Cortés, el uso de asientos altos estaba reservado para quien poseía la más alta jerarquía política y social.

${ }^{18}$ Joaquín Galarza, “Códices mexicanos 1," en Los códices de México (México: INAH, 1996), http://www.iconio.com/ ABCD/F/INDEX.PDF

${ }^{19}$ Los encargados de elaborar estos manuscritos, se llamaban Tlacuilos, que significa "el que escribía pintando", y fueron hombres y mujeres que poseían profundos conocimientos de su lengua y en el saber de su época, ya que asistían al calmecac, así también debían tener grandes aptitudes para el dibujo y la pintura; eran considerados como los perpetuadores del saber y se les destinaba a diversas instituciones en las que se especializaban en religión, economía o temas civiles; ellos mismos eran los lectores de esos documentos, puesto que el tlacuilo comprendía el significado de los pictogramas e interpretaba la información de acuerdo a lo que se requería.

Durante el periodo de conquista, muchos de estos documentos fueron destruidos sistemáticamente, ya fuera en la toma y saqueo de los amoxcalli (casas de libros, el equivalente a las bibliotecas actuales), así como en los llamados "autos de fe" que organizaban los frailes puesto que ellos consideraron estos libros como "obras del demonio". De esta destrucción se pudieron resguardar algunos cuantos códices, puesto que, los mismos frailes, cronistas e historiadores, 
como Sahagún, Motolinia y Torquemada entre otros, valoraron la información que contenían estas tiras, y recurrieron a los mismos tlacuilos y/o sabios indígenas para que les leyeran el contenido y les ayudaran a escribir sus propias crónicas. Otros más fueron enviados como regalos al rey de España, por lo que en total, se conservan menos de 20, y solo dos de ellos se resguardan en México.

${ }^{20}$ Manuel Toussaint, Arte Colonial en México, (México: UNAM, IIE, 1990), 17.

${ }^{21}$ Pablo Escalante Gonzalbo, Los Códices Mesoamericanos antes y después de la conquista, Historia de un lenguaje pictográfico. (México: Fondo de Cultura Económica, 2010), 143.

${ }^{22}$ Perla Valle, "Códice de Tlatelolco," Arqueología Mexicana 89, (2008): 66-70.

${ }^{23}$ Cabe mencionar que se elaboraron 3 originales, uno fue enviado al rey Felipe II, otro ejemplar permaneció en Tlaxcala y otro se envió a la Ciudad de México, aunque actualmente se desconocen su paradero, el ejemplar resguardado en la Biblioteca del Instituto Nacional de Antropología e Historia es una copia elaborada en 1773 por José Manuel Yllañez.

${ }^{24}$ Toussaint, Arte Colonial en México, 35. 